\title{
International Fire Research
}

\author{
JACK E. SNELL \\ Building and Fire Research Laboratory \\ National Institute of Standards and Technology \\ Gaithersburg, Maryland 20899, USA
}

\section{ABSTRACT}

This paper makes the case for international fire research, discusses the development and activities of the Forum for International Cooperation on Fire Research (FORUM) an informal association of heads of fire research organizations around the world, and suggests how the FORUM and IAFSS may support one another.

KEYWORDS: fire research; FORUM; international cooperation.

\section{INTRODUCTION}

Many believe the fire problem is well managed. Many say there are mounds of research results, and what is really needed is simply to apply them. There is some truth in both of these statements. But, I believe, the more relevant point is that we, i.e., all of us together, must confront the long unfinished agenda of fire research to assure fire safety at reasonable cost in our communities around the world. The critical steps in this process are developing "the" research agenda, amassing the resources needed to work it, doing the research, and implementing the results. Effective communication between those who do fire research and those who use the results is crucial to each step of this process. Clearly, the IAFSS is an important participant in it and there are many other important players as well.

The purpose of this paper is to examine means to facilitate this process. Specifically, the paper: 1) makes the case for international cooperation in fire research; 2) reports on the development, activities and status of the Forum for International Cooperation on Fire Research, or FORUM for short, an informal group of directors of fire research; and 3) discusses how the FORUM and IAFSS may support one another.

Working together we can realize the dream of engineered fire safety.

This paper is a contribution of the National Institute of Standards and Technology and is not subject to copyright. 
If you, as I, believe that international cooperation on fire research is essential to fulfilling the dream of fire science, we must be able to make the case for it to those with the resources we seek. Let me suggest six reasons why such international cooperation should be a priority.

1. Common threat and burden of fire. The appalling toll exacted by fire on the people and the economies of the world is the most compelling argument. This is a toll in loss of life, agonizing injury, and scarce resources that is needless in this day and age. Unfortunately, there is little comparative data on these costs and the little which is available is incomplete, addresses only a small fraction of the total cost and is outdated, much of the data is over a decade old [1].

Significant gains have been made in the earlier decades of this century so that conflagrations and mass deaths are relatively infrequent now. Yet, some believe the likelihood of a kilo-death fire is actually increasing. For instance, buildings are getting bigger and more complex, housing multi-function spaces including everything from residences to automobile garages, from energy conversion plants to child and elder care facilities. Also, vehicles are getting larger. Kilopassenger aircraft and massive new ships are being designed and built. Passenger submarines are becoming fashionable in isolated spots around the world. The likelihood of catastrophic damage from a major earthquake is increasing and historically, fire is the principal cause of deaths resulting from these natural disasters. Increasingly, safety standards are tending towards common world norms. Construction markets are becoming increasingly more global. Thus, the risks to people and businesses in any country are increasingly subject to the hazards of products made, or services provided, elsewhere.

Fire's toll has major economic as well as human dimensions. The total burden of fire in the U.S. has recently been estimated to exceed $\$ 128$ billion per year [2]! Other studies reveal the costs of providing fire safety are increasing even though the direct consequences of fire are getting lower. In the United States, the costs of providing fire services increased $68 \%$ and the costs of protecting buildings and products from fire increased 51\% in the period 1980 to 1986 , whereas the consumer price index rose just $30 \%$ in that same interval [3]. The expense to industry of fire safety, of product compliance and approval, of litigation and liability exposure, and the indirect consequences of fire on business and future market position are substantial. Every dollar spent needlessly on fire safety makes a business a dollar less competitive. Cities and communities simply can no longer afford unlimited increases in these costs nor the technologies which give rise to them, i.e., fire trucks and hoses and traditional practices, codes and standards. This situation is being experienced in many nations in the world. Thus, all stand to gain from fire research regardless of its national origin.

2. Too much/too big a problem for any one fire research center alone. No one fire research center anywhere in the world has the capability or resources to go it alone. The complexity and interdisciplinary character of fire make it one of the last frontiers of scientific inquiry among common everyday phenomena. In the decades of the fifties, sixties, and seventies, massive investments were made in research, facilities and instrumentation in response to space exploration and energy objectives. More recently, there has been increased attention to transportation and to environmental implications of energy conversion, both of which are largely combustion technologies. Yet, it is still not possible to predict the amount of carbon monoxide generated from burning a specified object or even its rate of burning, or the precise mechanisms of ignition or extinction. The tools we use for fire research at NIST, modestly one of the premier research facilities in the world, are among the most costly and sophisticated of any used for any program of research at NIST. Yet, typically fire research ranks low when priorities are set for research to expand the frontiers of science or emerging technologies. This situation is, sadly, common in our respective homelands. Cooperative research is, for many, the only alternative. 
3. Mutual benefit/stimulation in overcoming the inertia of traditional thinking, practices, and methods. Fire safety has a long and perhaps unfortunately too-well-remembered tradition. Most decision-makers see little benefit in departing from the tried and true methods of yesteryear, and are not motivated to rapid change or innovation. This is true of many institutions dedicated to preventing as well as to putting out fires. It tends to be true of the institutions dedicated to product testing and of standards organizations. Also, it is true for companies unwilling to risk seeing how their products may really perform in fire instead of in response to the carefully manipulated fire test conditions for which they were designed. Such traditions are antithetical to fundamental research, to innovation and new product development.

International competition works to offset many of these "traditional" influences. This is not something all of us can benefit from uniformly. However, since no one of us is fully duplicating the efforts of the others, all should find some benefit from international cooperation at least in areas of fundamental fire research and from movement towards a common set of scientifically-based fire safety evaluation methods and tests.

4. Fire safety engineering is the emerging language of fire safety. It includes providing the basis for testing and acceptance of products and materials; for design of buildings, vehicles, and facilities; for fire hazard and risk evaluation and management, and even for designing services and technologies for fire fighting and loss mitigation. These topics are predominant among the paper titles at this and the two earlier meetings of the IAFSS. As we all begin to speak the same language, the benefits to each of us will increase. This is a phenomena we have all observed in scientific and technical investigation in the past. As more researchers focus on an area, progress can become exponential. For example, fire modeling, flame spread, wall burning and heat release rate measurement are current cases in point.

5. World markets demand products that meet common standards for safety, compatibility and use. We all recognize the movement to a small number of highly competitive global markets, that may even in our lifetimes--if not, then in those of our children-become just one. Preoccupation among many here is with preparations for EC' 92 . Others are working just as hard to consolidate the markets of the Americas, and the Pacific Rim. This influence stimulates international cooperation on fire research. Fundamental research, i.e., precompetitive generic research, typically is not the basis on which businesses or even nations compete. They compete with products on the basis of quality, service and timeliness or availability. There is little incentive to keep one's competitors in the dark about fundamental developments as long as the advantage to be gained from commercial development of them are not lost. Alternatively, the more cooperation in fundamental research the broader the basis for all for differentiation and finding a unique niche in technology and product development.

6. It is a natural inclination of researchers, anyway. International recognition, as reflected by acceptance in peer reviewed journals, meetings etc., is one of the requisites used for promotion of researchers to the highest technical ranks within our Institute. I imagine this is true for most of the organizations represented here. This is not by accident. You are here because of your common commitment to lifelong learning, to excellence, and to fundamental understanding.

\section{THE FORUM}

With this background for the motivation for international fire research, let me now turn attention to a small group dedicated to your welfare and progress, the Forum for International Cooperation on Fire Research, or FORUM, for short. The FORUM is an informal group of individuals committed to reducing the burden of fire on society and the world economy through international cooperation on fire research and in the application of fire research results. It was 
formed in 1988 to bring together heads of fire research organizations throughout the world who are in a position of directing resources into fire research. Thus, you see from the outset that we have a lot in common. You want to do it and we want to see it done. Unfortunately, there is more that you want to do than we have resources to support, so we have at least allied interests in increased funding for fire research. Before moving on to how we might work together to meet these needs, let me first say a bit more about the FORUM, its members and background.

Like any group formed of persons of similar positions, the FORUM provides leaders of fire research organizations/programs the opportunity to share with and learn from peers. The FORUM meets annually to exchange technical and program information, work questions of mutual interest and seek opportunities for cooperative research and collaboration that advance our common objectives, including the transfer of research results and other actions to promote the findings of the FORUM. I have been asked to serve as Chairman and Ken Richardson of IRC Canada is the Secretary. Participants in FORUM meetings to date have been from CSIRO, Australia; IRC, Canada; VTT, Finland; CSTB, France; BRI and FRI, Japan; SINTEF, Norway; ITSEMAP, Spain; BRANDFORSK, Sweden; BRE, UK; and NIST and FMRC, USA.

These organizations collectively employ about 300 fire research professionals, maintain the world's best research, burn and fire test facilities and equipment, and are embedded within the world's finest scientific research organizations. Thus, collectively, these organizations very likely represent the level of resources needed to bring fire science and engineered fire safety to practical reality well within the lifetimes of many of us. More recently, about 25 additional organizations have been contacted to assess their potential interest in the activities of the FORUM (a listing of these organizations and tabulation of summary data from a number of them is presented later).

The intent has been to keep the group modest in size and informal to maximize opportunities for candid exchanges. At the same time, it is hoped that all who share this common role have the opportunity to do so.

The FORUM seeks open and effective exchanges on matters of mutual interest with other organizations including specifically, fire safety associations, standards bodies, and professional organizations. These may include topics such as strategic directions and goals for fire research, identification of specific research needs, assistance with research support, priority standards/test method development needs or issues, possible directions for standards development, implications of research results to standard practice in fire safety engineering, communication of research results, and priority needs in technology transfer. To date, such communications have included the following: ASTM; CEN/127; Conference of Fire Protection Associations (CFPA); CIB W-14; Comité European des Assurances, (CEA); IEC SC50D; IMO, IAFSS; ISO TC 92; National Fire Protection Association (NFPA); Society of Fire Protection Engineers (SFPE); Society of Fire Safety Engineers.

The first, 1988, meeting of the FORUM was held in conjunction with a conference jointly sponsored by the Society of Fire Protection Engineers and the Center for Fire Research (now a part of the Building and Fire Research Laboratory at NIST) on the application of fire research held in Gaithersburg, MD, USA. Following this meeting, a number of groups were solicited for inputs on fire research needs requiring international cooperation as preparation for our 1989 meeting at Brandforsk, in Stockholm, Sweden. At the Stockholm meeting, there was a strong consensus of participants to direct resources towards development of scientifically-based tools of "Fire Safety Engineering" as a means of reducing the limitations of restrictive, prescriptive standards and codes thus enabling optimum use of scarce fire protection resources. A principal topic of attention at the FORUM's 1990 meeting at the Fire Research Station, Borehamwood, England, was emerging fire test methods. The 1991 meeting is scheduled for FMRC, in Norwood, MA in July. 
From these meetings, the following set of five general objectives for the FORUM has emerged. I will briefly comment on the status of our activities associated with each of them.

1. Promote fire research. We are all concerned with quality. Responsiveness to real world needs and the timeliness of our products are crucial to each of us as well. As the case for internationalization of fire research becomes stronger, so will our mutual interests.

a. International fire research needs. The first product of the FORUM was a compilation of research needs based on the inputs from the groups noted above, specifically, IAFSS, NFPA, CIB W-14, ISO TC92 and SFPE. A summary of the responses is shown as Table 1 . Not surprisingly, work on each of these topics is now underway in one or more FORUM laboratories.

\section{TABLE 1 SUMMARY OF RESEARCH NEEDS}

\section{International Association for Fire Safety Science}

Fundamental fire research - studies in combustion, human behavior, smoke toxicity, and structural behavior

International exchange of researchers

Support of IAFSS

\section{CIB W14, ISO TC 92}

Heat release rate (HRR) data on materials

Correlation of HRR values with full scale burn tests

Computer modeling of smoke movement in buildings

Smoke toxicity measurement

Cooperative effort in developing fire models

Common philosophy for the development of international fire tests, standards, and product classification systems

Analyses of industrial fires, large scale fires, disasters

Joint fire tests of multi-story structures

Evaluation of fire safety software

Fire test data sets for model validation

Environmental impacts of fire protection technologies

Fires in space, transport, and underwater vehicles/facilities

Fire loads in developing countries

Fire retardants for indigenous building materials

National Fire Protection Association, USA

Halon/ozone problem

Warehouse fire protection

Flammable and combustible liquid storage

Modular design of fire models - common system/framework including relevant fire physics, structural performance, active system performance, building life cycle changes, etc.

Validation, quality control, and standardization of fire models

Common data generation procedures and databases

Behavioral and organizational factors in fire safety

Communications between researchers and research users, transfer of fire research results to users

\section{Society of Fire Protection Engineers}

Validation of models and tests - including guidelines for instrumentation and measurements Common fire model "format"/ architecture

Field modeling of fires 
b. Goals for fire research. The focus here is more on what we are trying to accomplish with international fire research and less on specific technical problems. The goals of fire research set by FORUM participants are paraphrased below in Table 2:

\section{TABLE 2 GOALS FOR INTERNATIONAL FIRE RESEARCH}

1. Break loose from restrictive practices and move to "engineered fire safety".

2. Achieve optimum use of fire safety investment.

3. Integrate fire safety engineering into the total design process.

4. Effectively transfer results of fire research into practice.

5. Reduce likelihood and impacts of disasters.

6. Minimize environmental impacts of fire protection.

7. Extend fire science to all aspects of fire safety.

8. Optimize use of international data on fire.

9. Raise competence of fire researchers through ongoing fundamental fire research.

10. Help fire services shift emphasis from fire suppression to prevention. measures.

Obviously, these are also means towards our common end of reducing the total burden of fire in the world. Note, that a number of these tasks require efforts well beyond the means of the FORUM participants.

c. Quantify economic burden of fire. The FORUM is committed to quantification of the burden of fire on society and the world economy. As a start, NIST commissioned a study of the total costs of fire safety in the United States and the impacts of NIST's fire research $[2,4]$. The central finding of the cost study is that fire costs society at least two to three times more than traditional estimates. Although detailed discussion of this report is beyond the scope of this paper, a summary tabulation from it is presented in Table 3 below:

TABLE 3 SUMMARY COSTS OF FIRE SAFETY IN THE UNITED STATES [2] (in Billions \$)

Losses:

Death and injury

Residential, Industrial, other property

Residential and Business interruption

Product liability

Insurance

Fire services

Deaths and injuries

Costs, including volunteer conversion

Preventative

Built into structures

Built into equipment, products

Fire maintenance

Other (standards, testing, etc.,)

Total 
Although individual items in the above may be unique to the USA, the costs of fire services, of approvals and compliance along with the costs of regulatory systems--which may not be fully accounted in this table--and the costs of loss of business and liability costs are experienced throughout the world and can be expected to continue to increase ahead of costs generally. The better accounting we can provide of the impacts of fire on society the more likely we are to be heard. The preliminary analysis of the impacts of NIST's fire research was conducted by Phil Schaenman of TriData [4]. The central finding of that study is that total savings of $\$ 5$ to $\$ 9$ billion per year can be traced to the NIST fire research program which costs less than $\$ 9$ million. per year. In this light, fire research is clearly a very productive investment!

d. Increase funding for fire research. At the Borehamwood meeting, FORUM participants shared concerns over the potential consequences of the continued, mostly downward, trend in funding of fire research. After some discussion, the following list of potential consequences/impacts was drafted:

Continued increases in the costs of fire to society.

Absence of adequate preplanning and/or mitigation strategies for ...

- a kilo-death fire,

- major fire losses from natural/other disasters.

More Hazmat (Hazardous Material) incidents.

Continued increase in the regulatory burden of traditional fire safety practices.

Inability to provide satisfactory quantitative tools for fire risk management.

Participants agreed that the gravity of these concerns needs to be communicated to regulatory officials, industry, politicians, and government agencies.

e. Support IAFSS and Interflam. These are the international premier forums for presenting fire research results and applications. The capabilities of the FORUM participants are limited, therefore it is desirable that we concentrate our energies in helping to support these efforts. Such support is in the form of staff submission of papers, funding, and participation. For example, in the three meetings of IAFSS to date, roughly $40-50 \%$ of the papers have been from or sponsored by a FORUM participant's organization.

f. Sponsorship of awards. The FORUM participants are pleased to provide financial assistance for the establishment of new cash awards in IAFSS, being offered for the first time this year, and funded initially by Brandforsk. We have worked closely with the leadership of IAFSS to coordinate these new awards with the existing IAFSS awards, and are hopeful that they will add motivation and stature to the work of this important body. In our next meeting, we will consider similar incentives for fire protection engineering through SFPE/SFSE.

2. Advance fire safety engineering. Accelerated development and acceptance of scientifically-based fire safety engineering methods and practice is one of the major motivations for international fire research. Already, the FORUM has taken several steps to move in this direction:

a. Coordinated development of fire models, measurement methods, data, etc. The sooner a common framework is available for definitions of terms and for phenomena, algorithms, interface protocols, measurement methods, data formats and structures, etc., the faster our collective progress will be. FORUM participants see this as a top priority area for cooperation and collaboration. To date, we have sponsored two compilations: one of fire models and the other technical issues in fire modeling, both drawn from inputs provided by our technical staffs. The former was prepared by Ray Friedman with the generous sponsorship of FMRC [5]. A 
summary table from this report is presented as Table 4. This compilation includes data sheets on each of 36 models from 9 countries.

TABLE 4 FORUM SURVEY OF COMPUTER MODELS FOR FIRE AND SMOKE: FRIEDMAN [5]

\begin{tabular}{|c|c|c|c|c|c|}
\hline Model & Country & Fire & Smoke & Endurance & Evacuation \\
\hline ASET & USA & $\mathrm{X}$ & $\mathrm{X}$ & & \\
\hline ASET-B & USA & $\mathrm{X}$ & $\mathrm{X}$ & & \\
\hline BF3D & USA & $\mathrm{X}$ & $\mathrm{X}$ & & \\
\hline $\mathrm{BRI2}$ & Japan & $\mathrm{X}$ & $\mathrm{X}$ & & \\
\hline CCFM.VENTS & USA & $\mathrm{X}$ & $\mathrm{x}$ & & \\
\hline CFIRE-X & Germany \& Norway & $\mathrm{X}$ & $\mathrm{X}$ & & \\
\hline CIFI & France & & $\mathrm{X}$ & & \\
\hline COFIL & Canada & & & $\mathrm{X}$ & \\
\hline COMPBRN III & USA & $\mathrm{X}$ & $\mathrm{X}$ & & \\
\hline COMPF 2 & USA & & & $\mathrm{X}$ & \\
\hline COMPSL & Canada & & & $\mathrm{X}$ & \\
\hline DSLAW & Sweden & $\mathrm{X}$ & $\mathrm{X}$ & & \\
\hline EVACS & Japan & $\mathrm{X}$ & & & $\mathrm{X}$ \\
\hline FAST & USA & $\mathrm{X}$ & $\mathrm{X}$ & & \\
\hline FIREX & Germany \& Norway & $\mathrm{X}$ & & & \\
\hline FIRST & USA & $\mathrm{X}$ & $X$ & & \\
\hline FISBA & France & $\mathrm{X}$ & & & \\
\hline FISCO-3 & Germany \& Norway & $\mathrm{X}$ & & & \\
\hline HARVARD VI & USA & $\mathrm{X}$ & $\mathrm{X}$ & & \\
\hline HAZARD I & USA & $\mathrm{d} / \mathrm{s}$ & $\mathrm{X}$ & & $\mathrm{X}$ \\
\hline INSTAI & Canada & . & & $\mathrm{X}$ & \\
\hline INSTCO & Canada & & & $\mathrm{X}$ & \\
\hline JASMINE & UK & $\mathrm{X}$ & $\mathrm{X}$ & & \\
\hline KAMELEON E-3D & Norway & $\mathrm{X}$ & $\mathrm{X}$ & & \\
\hline LAVENT & USA & $\mathrm{d} / \mathrm{s}$ & & & \\
\hline NAT & France & & & $\mathrm{X}$ & \\
\hline PALDET & Finland & $\mathrm{d} / \mathrm{s}$ & & & \\
\hline RADISM & UK & $\mathrm{d} / \mathrm{s}$ & & & \\
\hline
\end{tabular}




\begin{tabular}{||l|l|c|c|c|c||}
\hline Model & Country & Fire & Smoke & Endurance & Evacuation \\
\hline RECTST & Canada & & & $\mathrm{X}$ & \\
\hline R-VENT & Norway & & $\mathrm{X}$ & & \\
\hline SFIRE-4 & Sweden & $\mathrm{X}$ & & & \\
\hline SMACS & USA & & $\mathrm{X}$ & & \\
\hline SMKFLW & Japan & & $\mathrm{X}$ & & \\
\hline SQCON & Canada & & & $\mathrm{X}$ & \\
\hline TCSLBM & Canada & & & $\mathrm{X}$ & \\
\hline UNDSAFE & Japan & $\mathrm{X}$ & $\mathrm{X}$ & & \\
\hline Note: $\mathrm{d} / \mathrm{s}$ means "includes detector/sprinkler response" & & \\
\hline
\end{tabular}

Twenty of them calculate fire environment, mostly gas temperatures, and 19 address smoke movement. Copies of the report are available from FMRC and a publication on this work is expected. A report on the latter, fire modeling issues is in preparation under Ken Richardson's direction at IRC and should be available later this year.

FORUM participants are sponsoring development of the Fire Data Management System, FDMS, as common format for fire test data [6]. Specifically, the FDMS concept developed at NIST is being coded into software through the FRS. Once available, it will be tried and evaluated at a number of FORUM labs. The intent is to encourage standardization of data formats and the availability of reference fire test data sets for model development and validation. Just as soon as possible, the resulting codes will be brought to CIB for pre-standardization testing.

b. FORUM positions on key technical issues. FORUM participants are encouraging development of the cone calorimeter and related heat release rate measurement techniques, the LIFT apparatus, etc., and algorithms utilizing data from such devices as bases for fire performance methods of the future to replace ultimately historic reaction to fire test methods. The FORUM has communicated with ISO and CEN concerning the necessity of "rational" methods as an alternative to traditional tests. Specifically, the FORUM responded to a request for guidance from a European Commission working group and applauded its commitment to move forward with a "robust solution" for reaction to fire tests for interior linings. The FORUM outlined its view on how scientifically-based fire safety engineering tools can be applied for these purposes within five years by drawing on the work ongoing in participant's laboratories. The FORUM offered similar views on methods for the testing of upholstered furniture.

c. Support SFPE/SFSE. The health, vision, vitality and assertiveness of the leading fire safety engineering organizations in the world are critical to progress in fire safety. FORUM participants support the activities of these organizations, support participation of their staff in them, and will continue to work together with them to provide the tools and services needed to accelerate the advance of fire safety engineering. The FORUM is mindful that SFPE is in the process of completing a long range plan, or vision, for its future, and that discussions are underway between SFPE and SFSE concerning their mutual interests for the future. We heartily support these efforts and look forward to closer cooperation in the future. 
3. Facilitate technology transfer. This is a broad and generally undersupported aspect of fire research management, i.e., getting practical results out and into use. FORUM participants are cooperating in extending our effectiveness in this area. Ideally, technology transfer involves close cooperation between researchers and potential users of the results virtually from conception of the research project to its completion and through all stages of implementation. Current activities fall far short of this ideal.

a. Staff exchanges. Staff exchanges serve a multiplicity of objectives, however this is one of the very best vehicles for technology transfer. Typically, our lab at NIST is fortunate to have in excess of a dozen foreign guest researchers working on fire research annually. Unfortunately, financial limitations make it difficult for us to reciprocate on a one for one basis, nor do we feel that that is necessarily the best approach. A number of the other FORUM participant labs see it as preferable to send more staff out to other labs than they can accommodate on a visiting basis in their own facilities. Obviously, such exchanges need to be related to the specific needs and priorities of the labs involved no matter which way the traffic flows. I personally am strongly convinced of the value of such exchanges for the professional growth of the individuals involved as well as the benefits of their efforts to the labs they serve. I strongly urge, each of you to keep us mindful of the possibilities here.

b. Exchange of research information and results. FORUM participants are committed to full exchange of research reports and program plans, of close coordination among our libraries and channels for publication and presentation of results. The FORUM has contacted INFIRE, the international group coordinating fire research libraries, via SFPE for its suggestions on how we could more effectively and efficiently cooperate in this area.

c. Support intermediary organizations and users of fire research results. Each FORUM participant devotes much of his time to working with the organizations that use his results. Historically, these have been home-country specific, since the fire services, codes and standards organizations, industrial partners and regulatory systems differ widely among participant countries. However, the influences of globalization of markets I spoke of earlier should change much of this. I expect in the future we will devote more of our time to common issues regarding users of our products.

d. Investigation and disaster response. One very visible avenue for cooperation involving technology transfer is the area of fire investigations and disaster response. Clearly, any research lab director would be wise to draw on the resources of his international peers and colleagues when faced with a crisis. This was well illustrated recently by Ken Richardson, director of fire research at IRC who called out for help when confronted with a massive tire fire in Canada. His international FAX drew almost immediate help and the response was most appreciated.

4. Complement existing organizations. Much has been said already about the importance of FORUM communications with the many organizations that can help shape our programs, build support for them and make use of our results. A number of such groups have been discussed, already. Globalization is a powerful force in this direction. Clearly, an increasing fraction of the time at FORUM meetings will be devoted to such matters.

5. Optimize use of scarce resources. Cooperation and collaboration are essential for all of the FORUM participants. No one of us can afford to go it alone. No one of us has the capabilities to do it. Further, since most of what we do is in the realm of precompetitive generic research, little is to be gained from holding our cards closely to our chests or not share fully in what we are doing. The days when any one of us could come forward with a new method, device or even model and expect to capture exclusive rights or benefits are well behind us. At the same time, most FORUM participants work closely with industries in their own countries to help them 
enhance product quality to be competitive in global markets. This is as it should be. The FORUM serves as a mechanism to reduce the likelihood of misunderstandings and maintain a healthy balance between these sometime conflicting forces.

a. Summaries of FORUM lab capabilities, programs, etc. The FORUM has inventoried capabilities of the participant's laboratories and exchanged information on technical activities to increase collaborations among participant's labs. A summary of the types of such information compiled in this report is presented in the Appendix. Copies of this information may be available through the offices of the FORUM participants. A publication based on this information from all the fire research organizations around the world who chose to be included is planned.

b. Minimize needless duplication of research. Some duplication of effort is often necessary until the most promising directions for new technology can be discerned. But, fire research unlike many other areas of emerging technology addresses a common threat. We can all benefit from each other's work. Frequent sharing of information about projects, programs, and plans should go a long way to keeping duplication to a practical minimum.

c. Cooperative research. Much is to be gained from cooperative research between FORUM labs, and indeed much is already underway. Bilateral research programs and agreements have existed between a number of FORUM participants for decades. To stimulate further collaborations, at the Borehamwood meeting, FORUM participants compiled and ranked a list of topics for research collaboration, and have indicated their interest/willingness to proceed with such efforts as indicated on the summary sheet as shown on Table 5, below:

TABLE 5 TOPICS FOR RESEARCH COLLABORATION: SUMMARY OF 8 RESPONSES

\begin{tabular}{|l|c|c|}
\hline \multicolumn{1}{|c|}{ Topic } & Collaborate? & Have Resources? \\
\hline Reaction to fire - linings & 8 & 8 \\
\hline Atrium modeling/validation & 8 & 6 \\
\hline Validation of fire spread models & 8 & 4 \\
\hline Fire modeling & 7 & 5 \\
\hline Smoke control & 7 & 5 \\
\hline Fire risk analysis & 7 & 3 \\
\hline Large scale fires & 5 & 5 \\
\hline Halon & 5 & 4 \\
\hline Fire investigation practices & 5 & 4 \\
\hline Fire safety engineering framework & 4 & 3 \\
\hline Sprinklers vs vents & 4 & 2 \\
\hline Fire statistics & 6 & 1 \\
\hline
\end{tabular}

Participants were encouraged to pursue mutual interests as revealed in this exercise. We will revisit the status of such efforts in our next meeting. 
In summary, the FORUM intends to be proactive in advancing the cause of fire safety engineering through research directed to reduce the burdens of fire. It seeks to complement the roles and functions of existing fire safety bodies and looks forward to continued, mutually beneficial cooperation with all. We would welcome your suggestions concerning all of the above.

\section{THE FORUM AND IAFSS}

It should be obvious from the foregoing that FORUM participants have a vested interest in the IAFSS and your success. Similarly, to the extent the FORUM is able to increase the level and quality of international cooperation on fire research, as well as the total level of resources devoted to this important field, the IAFSS, and its members will benefit from the FORUM.

At the outset, I outlined a process for achieving the goal of "assured fire safety at reasonable cost." The critical steps are developing the research agenda, amassing the resources, doing the research, and implementing the results. Both the IAFSS and the FORUM conduct activities that support the first and last steps. Members of LAFSS are principally concerned with doing fire research and many as well with its implementation. Participants of the FORUM are mostly concerned with resources and priorities for research.

Figure 1 suggests, in an oversimplified way, how to reach our common goal of "assured fire safety." This is the desired end state, the limit in reducing the burden of fire, and we seek to reach it with a reasonable expenditure of resources.

\section{WHERE ARE WE GOING?}

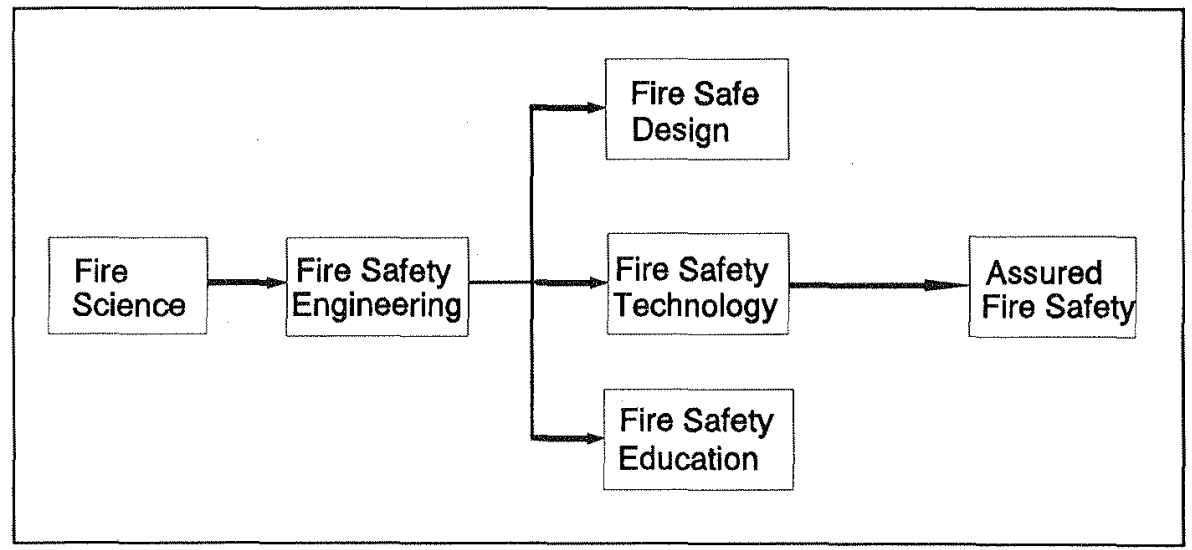

\section{FIGURE 1}

The technologies and practices which will make this possible will be very different from the ones upon which we have relied so heavily in the past. I am encouraged in this view by the general trend of fire research as reflected in the topics of papers selected for presentation before IAFSS meetings. A summary of the number of papers by topic is shown below on Table 6 . If we assume that IAFSS is truly at the frontier of fire research and technology development, then, this table should provide a glimpse of where we are headed. It also reflects the research priorities of FORUM participants, at least to the extent FORUM participants represent the largest single 
block of sponsors of this work, roughly $40-50 \%$ of the papers. In this, I see both good and bad news. The good news is the strong emphasis on fire physics and chemistry at these meetings. When one looks beyond the titles and examines the content of these papers it is clear that IAFSS is moving its attention to the fundamentals of fire science, as reflected by the total of the first and third lines of the table, i.e., 31-28-41 papers for the 1st, 2nd, and 3rd meetings of IAFSS. One even sees an occasional survey paper that analyses how we are doing.

The bad news is that we see a lot of emphasis still on problem-solving studies. Not that this is bad in itself. Rather, again looking beyond titles to content, there are/have been very few papers that suggest the framework or dimensions of fire science itself, or that address the generic

TABLE 6 IAFSS PAPERS OVER THE YEARS

\begin{tabular}{||l|c|c|c|}
\hline \hline Fire Physics & 1 st 85 & 2 nd 88 & 3rd 91 \\
\hline \hline Structural Behavior & 17 & 25 & 32 \\
\hline Fire Chemistry & 10 & 6 & 6 \\
\hline People-Fire Interactions & 14 & 3 & 9 \\
\hline Translation of Research into Practice & 9 & 7 & 5 \\
\hline Detection & 9 & 13 & 12 \\
\hline Specialized Fire Problems & 17 & 3 & 5 \\
\hline Statistics, Risk, Systems Analysis & 12 & 6 & 5 \\
\hline Smoke Toxicity and Toxic Hazard & 8 & 10 & 7 \\
\hline Suppression & 6 & 7 & - \\
\hline Smoke Movement & - & - & 5 \\
\hline TOTAL & 110 & 84 & 86 \\
\hline $\begin{array}{l}\text { Authored or Sponsored by FORUM } \\
\text { Participant (estimated) }\end{array}$ & 43 & & 42 \\
\hline Estimate & $(39 \%)$ & & $(49 \%)$ \\
\hline
\end{tabular}

precompetitive research that will underpin the new technologies that will make "assured fire safety" a reality. The first of these deficiencies, if you will, is relatively easy to fix and there are many of you who can do what is needed. The latter is a different matter for the underpinnings of the next generation fire safety technologies are founded in other disciplines or areas than those most of us represent. Fixing this problem may require bringing an even broader mix of talents to this already multi-faceted, multi-disciplinary field. I am thinking of people working at the frontiers of surface science, advanced sensing, artificial intelligence and expert systems, and chemistry and chemical process technologies. Also, I view the sustained representation in of papers on fire statistics, risk and systems analysis as laudable, but here too the content is mighty thin for a field so heavily dependent on advances in quantitative methods in these crucial areas. 


\section{SUMMARY}

In summary, the IAFSS is off to a productive and visible start. Also, the FORUM represents an effective means to enhance progress towards our common goals for fire safety. Moreover, there are numerous things IAFSS and the FORUM can do of mutual benefit and benefit of the publics we serve. I have noted the proactive intent of the FORUM participants. I have noted that we view IAFSS as representing the frontier of fire science and as the place to look for the stuff of fire safety engineering. Candidly, both IAFSS and the FORUM have major challenges before them. In fact, it is clear to me that each of us has a good bit of change to make before we reach our goals. Both of us have stakes in and roles to play in making those changes. Making them will require a significantly greater overall commitment of resources than presently we enjoy. The number one issue for the FORUM participants is how to fix that. We look forward to a continued and productive relationship.

We look forward to your input and we shall continue to support your quest for the fulfillment of fire science.

\section{REFERENCES}

1. Wilmot, R.T.D., World Fire Statistics Centre, Bulletin No. 8, December 1990.

2. Meade, William P., "A First Pass at Computing the Cost of Fire in a Modern Society," The Herndom Group, Inc., 209 North Columbia Street, Chapel Hill, NC 27514, March 1991.

3. Hall, John R. Jr., "Calculating the Total Cost of Fire in the United States," Fire Journal, Vol. 83, No. 2, March/April 1989.

4. Schaenman, Philip, "Estimated Impact of the Center for Fire Research Program on the Costs of Fire," TriData, 1500 Wilson Boulevard, Arlington, VA 22209, January 1991.

5. Friedman, Raymond, "Survey of Computer Models for Fire and Smoke," Factory Mutual Research Corporation, Norwood, MA, Technical Report, March 1990.

6. Babrauskas, V., "The Fire Data Management System (FDMS), pp. 1-5 in International Conference on Fires in Buildings. Intersicence Communications, Ltd, Toronto (1989). Also appears in: pp. 32-37 in Report of the Fourth CIB W14 Workshop on Fire Modeling; Conseil International du Batiment (CIB) Commission W14 on Fire (NISTIR 4338), J.G. Quintiere, ed. [U.S.] National Institute of Standards and Technology (1990).

7. "Summaries of Strategic Objectives, Research Programmes and Technical Facilities of Organizations Participating in the FORUM," Forum for International Cooperation on Fire Research, May 1990. 
Appendix

FORUM PARTICIPANT ORGANIZATIONS - SUMMARY DATA ${ }^{1}$ [Reference 7]

\begin{tabular}{|c|c|c|c|c|c|}
\hline Country & Organization & $\mathrm{In}^{2}$ & $\mathrm{Role}^{3}$ & Prof/Total Staff & Special Fentures \\
\hline Australia & FTP, CSIRO & G & $\mathrm{R}, \mathrm{T}$ & $15 / 30$ & Fire Modeling, Reaction and Resistance to Fire Testing, Smoke Control, Room Burns. \\
\hline Canada & FRS, IRC & $\mathrm{G}$ & $\mathbf{R}, \mathbf{T}$ & $12 / 27$ & $\begin{array}{l}\text { Large Burn Facility }\left(9300 \mathrm{M}^{3} \text { ), Smoke Tower (10 Story), Reaction and Resistance to Fire }\right. \\
\text { Tests, Ext. Wall Test, Fire Modeling. }\end{array}$ \\
\hline Finland & FTL, VTT & $\mathrm{G}$ & $\mathbf{R}, \mathbf{T}$ & $20 / 40$ & Fires in Tunnels, Reaction and Resistance to Fire Tests. \\
\hline France & FS, CSTB & $G$ & $\mathbf{R}, \mathbf{T}$ & $5 / 30$ & $\begin{array}{l}\text { Risk Analysis, Fire Modeling, Smoke Propagation Modeling, Reaction and Resistance to } \\
\text { Fire Tests, Smoke Tower. }\end{array}$ \\
\hline Japan & FR, BRI & G & $\mathrm{R}, \mathrm{T}$ & $16 / 174$ & Performance Methods, Multi-Function Burn and Smoke Transport Facility, Fire Modeling. \\
\hline Japan & FRI, FDI & G & $\mathbf{R}, \mathbf{T}$ & $35 / 53$ & $\begin{array}{l}\text { Multi-Function Burn Facility }\left(11520 \mathrm{M}^{3}\right) \text {, Technology for Fire Services, Extinguishment } \\
\text { Facility }\left(8550 \mathrm{~m}^{3}\right) \text { with } 12 \mathrm{M} / \mathrm{s} \text { Winds. }\end{array}$ \\
\hline Norway & SINTEF & I (oil) & $\mathbf{R}, \mathbf{T}$ & $15 / 25$ & $\begin{array}{l}\text { Fire Modeling and Test Methods, EURIFIC, Off Shore Structures, New Burn Facility } \\
\left(16200 \mathrm{M}^{3}\right) \text {. }\end{array}$ \\
\hline Spain & ITSEMAP & Ins. & R,T,E & $14 / 20$ & $\begin{array}{l}\text { Expert System for Hi-Rise Emergency Mgt., Burn Facility, InterAmerican Assn. of Fire } \\
\text { Research and Test Centers. }\end{array}$ \\
\hline Sweden & BRANDFORSK & G/I & $\operatorname{Re} \mathrm{Mgt}$ & $2 / 3$ & $\begin{array}{l}\text { Broad International Fire Research Program - } 70 \text { Projects in } 5 \text { Countries, Experimental and } \\
\text { Theoretical Studies. }\end{array}$ \\
\hline UK & FRS, BRE & $G$ & $R, T$ & $50 / 100$ & $\begin{array}{l}\text { Field Modeling, Cardington Facility }\left(10^{6} \mathrm{M}^{3}\right) \text {, Investigations, Reaction to Fire, Industrial } \\
\text { Hazards. }\end{array}$ \\
\hline USA & CFR, NIST & $\mathrm{G}$ & $\mathbf{R}$ & $69 / 90$ & $\begin{array}{l}\text { Fundamental and Applied Fire Research, Fire Prediction and Modeling, HAZARD I, } \\
\text { FPETOOL, Research Burn Facility. }\end{array}$ \\
\hline USA & FMRC & Ins. & R,T,Ri Mgt & $40 / 217$ & $\begin{array}{l}\text { Applied and Fundamental Fire Research, Risk Analysis, Multi-Function Burn Facility, } \\
\text { Sprinklers, Industrial Loss Control. }\end{array}$ \\
\hline
\end{tabular}

